\title{
The Influence of Androgen Deprivation Therapy on Prostate Size and Voiding Symptoms in Prostate Cancer Patients in Korea
}

\author{
Hoon Choi ${ }^{1}$, Hong Chung ${ }^{2}$, Jae Young Park ${ }^{1}$, Jeong Gu Lee ${ }^{1}$, Jae Hyun Bae ${ }^{1}$ \\ ${ }^{1}$ Department of Urology, Korea University Ansan Hospital, Korea University College of Medicine, Ansan, Korea \\ ${ }^{2}$ Department of Urology, Konkuk University Hospital, Chungju, Korea
}

Purpose: The goal of this study is to investigate the effects of androgen deprivation therapy (ADT) on total prostate volume and lower urinary tract symptoms (LUTS).

Methods: Between January 2007 and June 2014, 110 patients who received androgen deprivation treatment were enrolled in this retrospective study. Clinical parameters and urodynamic parameters along with changes at follow-up were analyzed. Factors such as reduction in prostate volume, changes in LUTS, and prostate volume tertiles were compared 1 year after ADT.

Results: After ADT, the total International Prostate Symptom Score (IPSS) score decreased from 17.45 to 12.21 and the IPSS voiding subscore decreased from 9.16 to 6.24 . Maximal uroflow rate increased from 8.62 to $11.50 \mathrm{~mL} / \mathrm{sec}$ and residual urine also reduced significantly by $29.34 \mathrm{~mL}$. Change in prostate size was more prominent $(-51.14 \%)$ in the patients with less than 1 year of ADT $(n=21)$ than those who had more than 1 year of treatment $(n=89,-44.12 \%)$. The decrease in the IPSS voiding subscore was greater within 1 year of ADT than after 1 year of treatment ( -4.10 vs. -2.65$)$. The differences were more significant in the $30-50$ group $(n=59)$ and $>50$ g group $(n=11)$ than the $<30$ group $(n=40)$ of the IPSS voiding subscore improvement $(-3.76,-4.91$ vs. -2.10$)$, and maximal uroflow rate improvement $(2.78,2.90$ vs 1.49$)$.

Conclusion: ADT resulted in statistically significant clinical improvement in terms of prostate volume, urodynamic parameters, and LUTS for patients with prostate cancer when analyzed by ADT duration and prostate volume.

Keywords: Androgen Deprivation Therapy; Prostate Neoplasms; Prostate Volume

- Research Ethics: This study was performed from January 2007 to June 2014 in accordance with the protocol approved by the Ethics and Research Committee of Korea University Medical Center Ansan Hospital Institutional Review Board (AS13173-001).

- Conflict of Interest: No potential conflict of interest relevant to this article was reported.

\section{INTRODUCTION}

Prostate cancer is hormone sensitive and can be treated with androgen deprivation by blocking the androgen receptor (AR) or by reducing the production of testosterone. Androgen deprivation therapy (ADT) is achieved by using luteinizing hormone-releasing hormone (LHRH) analogs and antiandrogens, which reduces testosterone to castration levels and thus inhibits the growth of prostate cancer [1]. On a practical level, reducing total prostate volume (TPV) by using ADT could aid in the more efficient delivery of radiation or neo-adjuvant treatment before radical surgery [2].

Prostate volume is one of the most extensively studied factors for prostate-related symptomatic relief. Without a doubt, patients with symptomatic benign prostatic hyperplasia (BPH) who receive dutasteride or finasteride experience a significant

Corresponding author: Jae Hyun Bae (iD http://orcid.org/0000-0001-9862-3545 Department of Urology, Korea University Hospital, Korea University College of Medicine, 123 Jeokgeum-ro, Danwon-gu, Ansan 15355, Korea E-mail: doc71377@hanmail.net / Tel: +82-31-412-5190 / Fax: +82-31-412-5194 Submitted: May 9, 2016 / Accepted after revision: July 18, 2016
This is an Open Access article distributed under the terms of the Creative Commons Attribution Non-Commercial License (http://creativecommons.org/licenses/by-nc/4.0/) which permits unrestricted non-commercial use, distri-
bution, and reproduction in any medium, provided the original work is properly cited. 
decrease in prostate gland size and subsequent improvement in symptoms $[3,4]$.

In the majority of cases, prostate cancer arises in the periphery, so patients often remain asymptomatic for long periods. Nevertheless, progressive prostate cancer can invade adjacent structures such as the transitional zone of the prostate or the bladder, resulting in voiding problems $[5,6]$. Moreover, the prevalence of prostate cancer increases with age as does the growth of benign prostate tissue in patients with $\mathrm{BPH}$. Therefore, the shared mechanisms of both $\mathrm{BPH}$ and prostate cancer should be considered [7].

To date, limited data exists about the effect of ADT on lower urinary tract symptoms (LUTS) in prostate cancer, especially mid- to long-term data and data within the Asian population, despite expectations of the additional urodynamic benefits of ADT. This study assessed the efficacy of ADT in reducing TPV and LUTS in patients with prostate cancer.

\section{MATERIALS AND METHODS}

This study was performed from January 2007 to June 2014 in accordance with the protocol approved by the Ethics and Research Committee of Korea University Medical Center Ansan Hospital. Patients who received ADT for metastatic or locally advanced prostate cancer for more than 3 months during the study period were enrolled. All of the enrolled patients were screened for medication status that could influence voiding function. Patients with a biochemical relapse with refractory to hormone therapy within the treatment period, urinary catheterized state, treating or treated with 5- $\alpha$ reductase inhibitors or alpha-adrenoreceptor blockers within the previous month, and with a life expectancy of less than 12 months were excluded.

The following were determined about each patient initially: medical history, Gleason score, positive core number, prostatespecific antigen (PSA) and TNM stage, initial International Prostate Symptom Score (IPSS), functional bladder capacity, voiding frequency, maximal uroflow rate (Qmax), and postvoid residual (PVR) urine volume by use of diagnostic ultrasound. All patients received $3.75 \mathrm{mg}$ of Leuprolide acetate injected subcutaneously into the abdominal wall each month and $50 \mathrm{mg}$ of oral bicalutamide daily.

Androgen deprivation period, age at diagnosis, Gleason score, positive core number, PSA, factors related to voiding, changes in the Qmax and residual urine, and urinary symptoms using the IPSS were analyzed.
Prostate volume $(\mathrm{mL})$ was measured and an integrated volumetric program was automatically calculated by using the following formula: volume width $\times$ length $\times$ height $\times 0.5236$ [8]. All of the variables, uroflometric parameters, and symptom scores by prostate volume and treatment period were analyzed. Comparisons were made between parameters measured less than 1 year after ADT and those measured more than 1 year after treatment. Additionally, variables were analyzed across tertile distributions of prostate size defined by weight: $<30 \mathrm{~g}, 30-$ $50 \mathrm{~g}$, and $>50 \mathrm{~g}$.

All values are presented as mean \pm standard deviation. Values of the clinical factors were analyzed by using an independent $\mathrm{t}$ test, Pearson chi-square test and analysis of variance to determine the significance of differences between groups, and a Pvalue of $<0.05$ was considered to be statistically significant. Statistical analyses were performed using SPSS ver. 14.0 (SPSS Inc., Chicago, IL, USA).

\section{RESULTS}

The mean follow-up period was 20.4 months. Baseline characteristics and changes in parameters after ADT for all 110 patients are shown in Table 1.

The PSA level decreased from 64.89 to $8.01 \mathrm{ng} / \mathrm{mL}$ and prostate size decreased significantly from 36.65 to $19.49 \mathrm{~g}$ during the study period. The average reduction of prostate size after ADT was $46.82 \%$. Total IPSS score decreased from 17.45 to 12.21 , and the IPSS storage subscore decreased from 7.65 to 5.54, but was not statistically significant; only the reduction in IPSS voiding subscore was statistically significant (9.83 to 6.70). Quality of life scores and functional urine volume, daytime frequency, and nocturia times showed no significant change, but maximal uroflow rate increased from 8.62 to $11.50 \mathrm{~mL} / \mathrm{sec}$, and residual urine also reduced significantly by $29.34 \mathrm{~mL}$.

Comparative analysis based on ADT duration showed that changes in prostate size were more prominent within 1 year of ADT than after more than 1 year of treatment $(51.14 \%$ vs. $44.12 \%$ ). The IPSS voiding subscore improvement was also greater in patients who had received ADT for less than 1 year than in patients who had been treated for more than 1 year ( -4.10 vs. -2.65$)$. Further analysis showed no other differences between the 2 groups (Table 2).

A comparative analysis based on prostate volume demonstrated that changes in prostate size reduction was higher in the $30-50 \mathrm{~g}$ size group and the $>50 \mathrm{~g}$ size group than in patients 
Table 1. Baseline characteristics and parameter changes of 110 patients after androgen deprivation therapy

\begin{tabular}{lccc}
\hline Variable & Baseline & After ADT & P-value \\
\hline PSA (ng/mL) & $64.89 \pm 21.15^{*}$ & $8.01 \pm 3.17$ & $<0.01$ \\
Prostate volume $(\mathrm{mL})$ & $36.65 \pm 14.59^{*}$ & $19.49 \pm 12.47$ & $<0.01$ \\
IPSS total score & $17.45 \pm 8.56^{*}$ & $12.21 \pm 7.6$ & 0.04 \\
IPSS voiding subscore & $9.83 \pm 6.11^{*}$ & $6.70 \pm 5.06$ & 0.02 \\
IPSS storage subscore & $7.65 \pm 3.75$ & $5.54 \pm 3.48$ & 0.29 \\
Quality of life score change & $4.06 \pm 1.98$ & $3.15 \pm 0.97$ & 0.07 \\
Functional bladder capacity change $(\mathrm{mL})$ & $309.36 \pm 107.54$ & $314.03 \pm 110.03$ & 0.83 \\
Day time voiding frequency & $6.01 \pm 0.79$ & $5.93 \pm 0.80$ & 0.29 \\
Night time voiding frequency & $2.82 \pm 0.86$ & $2.73 \pm 0.91$ & 0.63 \\
Qmax (mL/sec) & $8.62 \pm 5.43$ & $11.50 \pm 4.71^{*}$ & 0.04 \\
Postvoid residual volume $(\mathrm{mL})$ & $60.41 \pm 20.43$ & $31.07 \pm 10.42^{*}$ & 0.02 \\
\hline
\end{tabular}

Values are presented as mean \pm standard deviation.

$\mathrm{ADT}$, androgen deprivation therapy; PSA, prostate-specific antigen; IPSS, International Prostate Symptom Score; Qmax, maximal uroflow rate. ${ }^{*} \mathrm{P}<0.05$, baseline vs. after ADT.

Table 2. Comparison of clinical effects by androgen deprivation therapy duration

\begin{tabular}{|c|c|c|}
\hline \multirow{2}{*}{ Variable } & \multicolumn{2}{|c|}{ ADT duration } \\
\hline & Less than 1 year $(n=21)$ & More than 1 year $(n=89)$ \\
\hline Follow-up period (mo) & $8.90 \pm 2.12$ & $23.83 \pm 24.18$ \\
\hline Age (yr) & $74.58 \pm 7.48$ & $75.88 \pm 6.34$ \\
\hline $\begin{array}{l}\text { Stage } \\
\mathrm{T} \leq 2 \\
\mathrm{~T} \geq 3 \\
\mathrm{M} 0 \\
\mathrm{M} 1\end{array}$ & $\begin{array}{r}5(23.8) \\
16(76.2) \\
4(19.0) \\
17(81.0)\end{array}$ & $\begin{array}{l}18(20.2) \\
71(79.8) \\
15(16.9) \\
74(83.1)\end{array}$ \\
\hline Gleason score & $7.52 \pm 1.27$ & $7.61 \pm 1.20$ \\
\hline Positive core number & $2.36 \pm 1.02$ & $2.40 \pm 0.95$ \\
\hline PSA change (ng/mL) & $-60.16 \pm 23.80$ & $-54.31 \pm 17.92$ \\
\hline Prostate volume change (\%) & $-51.14 \pm 8.73$ & $-44.12 \pm 7.33^{*}$ \\
\hline IPSS total score change & $-7.27 \pm 0.72$ & $-5.23 \pm 0.58$ \\
\hline IPSS voiding subscore change & $-4.10 \pm 0.23$ & $-2.65 \pm 0.50^{*}$ \\
\hline IPSS storage subscore change & $-3.07 \pm 0.77$ & $-1.97 \pm 0.62$ \\
\hline Quality of life score change & $-0.09 \pm 0.02$ & $-0.12 \pm 0.03$ \\
\hline Functional bladder capacity change (mL) & $-6.37 \pm 1.70$ & $5.86 \pm 1.10$ \\
\hline Day time voiding frequency change & $-0.10 \pm 0.09$ & $-0.09 \pm 0.08$ \\
\hline Night time voiding frequency change & $-0.09 \pm 0.11$ & $-0.09 \pm 0.12$ \\
\hline Qmax change $(\mathrm{mL} / \mathrm{sec})$ & $2.74 \pm 0.19$ & $2.89 \pm 0.32$ \\
\hline Postvoid residual change (mL) & $-26.60 \pm 8.37$ & $-31.33 \pm 2.95$ \\
\hline
\end{tabular}

Values are presented as mean \pm standard deviation or number (\%).

$\mathrm{ADT}$, androgen deprivation therapy; PSA, prostate-specific antigen; IPSS, International Prostate Symptom Score; Qmax, maximal uroflow rate. ${ }^{*} \mathrm{P}<0.05$, less than 1 year vs. more than 1 year. 
Table 3. Comparison of clinical effect of androgen deprivation therapy by prostate size

\begin{tabular}{|c|c|c|c|}
\hline \multirow{2}{*}{ Variable } & \multicolumn{3}{|c|}{ Prostate size } \\
\hline & $<30 \mathrm{~g}(\mathrm{n}=40)$ & $30-50 \mathrm{~g}(\mathrm{n}=59)$ & $>50 \mathrm{~g}(\mathrm{n}=11)$ \\
\hline Age (yr) & $73.26 \pm 6.58$ & $74.73 \pm 7.06$ & $75.43 \pm 7.35$ \\
\hline \multicolumn{4}{|l|}{ Stage } \\
\hline $\mathrm{T} \leq 2$ & $9(22.5)$ & $12(20.3)$ & $2(18.1)$ \\
\hline $\mathrm{T} \geq 3$ & $31(77.5)$ & $47(79.7)$ & $9(81.9)$ \\
\hline M0 & $7(17.5)$ & $10(16.9)$ & $2(18.1)$ \\
\hline M1 & $33(82.5)$ & $49(83.1)$ & $9(81.9)$ \\
\hline Gleason score & $7.20 \pm 1.09$ & $7.81 \pm 1.45$ & $7.82 \pm 1.32$ \\
\hline Positive core number & $2.20 \pm 0.97$ & $2.47 \pm 1.15$ & $2.51 \pm 1.04$ \\
\hline PSA change (ng/mL) & $-54.31 \pm 21.80$ & $-58.12 \pm 16.75$ & $-57.45 \pm 17.43$ \\
\hline Prostate volume change (\%) & $-37.40 \pm 4.46$ & $-47.55 \pm 10.11^{*}$ & $-48.45 \pm 11.33^{\dagger}$ \\
\hline IPSS total score change & $-4.22 \pm 1.23$ & $-6.56 \pm 1.76$ & $-7.09 \pm 2.02$ \\
\hline IPSS voiding subscore change & $-2.10 \pm 0.23$ & $-3.76 \pm 0.68^{*}$ & $-4.91 \pm 0.65^{\dagger}$ \\
\hline IPSS storage subscore change & $-2.03 \pm 0.56$ & $-1.83 \pm 0.43$ & $-2.36 \pm 0.52$ \\
\hline Quality of life score change & $-0.07 \pm 0.01$ & $-0.11 \pm 0.09$ & $-0.12 \pm 0.12$ \\
\hline Functional bladder capacity change $(\mathrm{mL})$ & $-15.75 \pm 4.34$ & $17.63 \pm 6.33$ & $-12.78 \pm 3.76$ \\
\hline Day time voiding frequency change & $-0.23 \pm 0.07$ & $0.13 \pm 0.05$ & $-0.89 \pm 0.12$ \\
\hline Night time voiding frequency change & $-0.05 \pm 0.02$ & $-0.03 \pm 0.01$ & $-0.24 \pm 0.08$ \\
\hline Qmax change (mL/sec) & $1.49 \pm 0.01$ & $2.78 \pm 0.23^{*}$ & $2.90 \pm 0.31^{\dagger}$ \\
\hline Postvoid residual change (mL) & $-21.81 \pm 8.37$ & $-29.78 \pm 7.06$ & $-26.83 \pm 2.95$ \\
\hline
\end{tabular}

Values are presented as mean \pm standard deviation or number (\%).

PSA, prostate-specific antigen; IPSS, International Prostate Symptom Score; Qmax, maximal uroflow rate.

${ }^{*} \mathrm{P}<0.05,<30$ g vs. $30-50$ g. ${ }^{\dagger} \mathrm{P}<0.05,<30$ g vs. $>50$ g.

with an initial prostate volume of $<30 \mathrm{~g}(-47.55 \%,-48.45 \%$, and $-37.40 \%$, respectively), as was IPSS voiding subscore improvement $(-3.76,-4.91$, and -2.10 , respectively), and Qmax improvement $(2.78,2.90$, and 1.49 , respectively). Other factors showed no differences among the 3 groups (Table 3 ).

\section{DISCUSSION}

Prostate cancer is typically a hormone-responsive tumor. ADT reduces the activation of androgen-sensitive growth in both cytostatic and cytotoxic pathways by blocking the AR or decreasing the production of circulating testosterone for hormonesensitive cancer cells [1]. ADT is often used as a neo-adjuvant treatment before prostate brachytherapy in case of poor geometry or definite operation in higher risk pathologic features. In general, it is LHRH agonists and a basic form of ADT that stimulate pituitary LHRH receptors. LHRH agonists suppress testosterone by suppressing the pituitary gland, thereby inhibiting the release of luteinizing hormone and follicular stimulating hormone [9]. Bicalutamide, a nonsteroidal compound with a high affinity for the AR, directly targets the AR ligand-binding domain and inhibits the transcription of androgen response elements [10].

In general, almost $70.0 \%$ of prostate cancer arises from the peripheral zone, usually far from the bladder outlet. Nevertheless, $55.6 \%$ of prostate cancer patients have minimal voiding problems, $37.1 \%$ of patients have moderate, and $7.3 \%$ patients have severe voiding problems [11].

Prostate cancer has exhibited the greatest increase in its incidence in Korea, and the well-being among prostate cancer patients is a frequently occurring and important issue as is effective cancer treatment. Therefore, the addictive benefits of hormonal treatment and its clinical application warrant clarification. Theoretically, ADT can improve LUTS in prostate cancer and the effects of ADT might be associated with a complete decrease in prostate size rather than a reduction in the cancer volume per se [12]. Ebara et al. [13] reported that the rates of volume reduction were $32.0 \%$ for the LHRH agonist monotherapy, 
$18.1 \%$ for the antiandrogen monotherapy, and $41.2 \%$ for combination therapy. The reduction in TPV was $29 \%$ three months after ADT, 31\% for LHRH agonist monotherapy and 28\% for those treated with an LHRH agonist plus an antiandrogen. The differences were not significant [14]. Another study revealed that combination therapy achieved $39.0 \%$ volume reduction at 12 weeks [15]. Generally, reports showed that after 3 to 8 months of ADT, including an LHRH agonist with or without an antiandrogen, results in a prostate size decrease from $20 \%-$ $50 \%$ [16-18].

The kind of androgen deprivation that is more efficient and the duration of administration for adequate TPV reduction remain unclear. There was difference in volume reduction among those who received 4 months or less of androgen deprivation (20\%) compared to those who received ADT for 6 months or greater (27\%) [19]. The maximal degree of volume reduction was achieved by the use of combination ADT for more than 6 months but there was no significant difference associated with the duration of treatment [13]. Our data showed a $-51.14 \%$ prostate size reduction less than 1 year after $\mathrm{ADT}$ and a reduction of $-44.12 \%$ after more than 1 year. There could be regrowth of prostate tissue or a refractory mechanism working against the ADT-induced prostate size reduction. As for the volume changes, initial prostate gland volume before beginning the androgen deprivation positively correlated significantly with percentage volume reduction due to androgen deprivation [20].

Patients with larger volumes had a greater reduction in TPV compared to those with smaller glands ( $41 \%$ vs. $14 \%$ ). Another study revealed that decreasing the volume of the prostate is greater in 50- to $60-\mathrm{mL}$ patients as a neo-adjuvant $\mathrm{ADT}$ [21]. Our data showed that changes in prostate size reduction were $-37.40 \%$ in patients with an initial prostate weight of $<30 \mathrm{~g}$, $-47.55 \%$ in those with an initial prostate size of $30-50 \mathrm{~g}$ and $-48.45 \%$ in patients whose prostate started at $>50 \mathrm{~g}$. Our study is the first one to compare the volume change in 3 classes.

Consequently, mechanical effects by ADT eventually relieve the LUTS and uroflowmetric parameters. One study reported statistically significant changes in urodynamic parameters: a $38 \%$ increase in maximal flow rate, $36 \%$ decrease in residual volume, $15 \%$ decrease in voiding frequency, and $67 \%$ decrease in symptom score after 12 months of ADT [22]. The mean total IPSS showed progressive decreases by 2.7 points and the Benign Prostate Hyperplasia Impact Index was reduced by 1.16 point from baseline after ADT [15]. Another study showed that the IPSS score improved by 8.6 and quality of life score by 0.6 with increases in Qmax ( $+1.3 \mathrm{~mL} / \mathrm{sec}$ from baseline) [23]. Therefore, the overall efficacy of ADT on prostate issues and urodynamic findings translates into improved patient quality of life. The efficacy of ADT treatment has been established in a few clinical trials but its effect on LUTS has not been studied properly.

In the current study, the total IPSS score decreased from 17.45 to 12.21 , and there was a statistically significant decrease in IPSS voiding subscore from 9.83 to 6.70 . The maximal uroflow rate increased from 8.62 to $11.50 \mathrm{~mL} / \mathrm{sec}$ and residual urine was significantly reduced by $29.34 \mathrm{~mL}$. The IPSS voiding subscore was more prominent in patients who had received ADT for less than 1 year $(-4.10)$ than in those who had been treated for more than 1 year $(-2.65)$. Being the first study to compare urodynamic parameter changes in tertile classes by prostate volume in our data, IPSS voiding subscore improvements were -2.10 in the $<30$ g group, -3.76 in the $30-50$ g group, and -4.91 in the $>50$ g group, respectively. Qmax improvements were 1.49 in the $<30 \mathrm{~g}$ group, 2.78 in the $30-50 \mathrm{~g}$ group, and 2.90 in the $>50$ g group.

These clinical effects might also be based on another potential mechanism. Gonadotropin-releasing hormone $(\mathrm{GnRH})$ receptors have been found on prostate smooth muscle cells and on the bladder mucosa in animals and humans. Indirect effects on testosterone deprivation by pituitary receptors might suggest beneficial effects on the static and dynamic components of bladder outlet obstruction [24,25]. GnRH receptor blockade on these cells has been associated with down-regulation of proinflammatory cytokines, various growth factors, and alpha-adrenoreceptors [26,27]. GnRH metabolism is involved in the deprivation of experimental detrusor hyperactivity induced by prostaglandin E2 instillation. The mechanism is presumed to include the effects on cells or transmitters involved in physiological mechano-afferent activation. Therefore, TPV reduction to $\mathrm{ADT}$ is not the only mechanism that can provide symptomatic relief and peripheral effects on voiding. Changes bladder and prostate tissue induced by ADT cause urinary morbidity, and irritative and obstructive urinary symptoms are frequent complaints of patients with prostate cancer.

This study has limitations, including the fact that there was no placebo control group for comparison. Despite patients being enrolled in designated periods during follow-up, the study design is retrospective and therefore the study period was variable. In addition, we do not have within 1 year and more than 1 
year data on the same patient. Finally, the control of medication was relatively insufficient because most of the senile patients took various types of medications for chronic diseases and many uninvestigated variables can affect the results of this study.

Conversely, the profiles of ADT treatments were effective in life quality improvement as expected for male patients with LUTS secondary to prostate cancer. Our findings suggest that the improvement in LUTS could be caused by a more prominent shrinkage of the prostate, as well as neuro-physiological and consequently improved voiding parameters. Selecting the patients who will benefit from ADT need their baseline possibility of disease progression along with the risks and benefits of medication therapy to be estimated. Prostate volume apparently was found to be the most significant factor and was associated with age and PSA level. Other parameters such as the Qmax, PVR, or symptom score must also be deliberated. The advantages of ADT in providing clinically meaningful LUTS relief demands more investigation in the future including more specified studies.

In conclusion, meaningful changes in prostate volume, urodynamic parameters, and LUTS were observed after ADT. The differences observed by ADT duration and initial prostate volume were statistically significant.

\section{REFERENCES}

1. Labrie F, Bélanger A, Luu-The V, Labrie C, Simard J, Cusan L, et al. Gonadotropin-releasing hormone agonists in the treatment of prostate cancer. Endocr Rev 2005;26:361-79.

2. Sanghani MV, Schultz D, Tempany CM, Titelbaumd D, Renshawe AA, Loffredoa M, et al. Quantifying the change in endorectal magnetic resonance imaging-defined tumor volume during neoadjuvant androgen deprivationtherapy in patients with prostate cancer. Urology 2003;62(3 Suppl):487-91.

3. McConnell JD, Roehrborn CG, Bautista OM, Andriole GL Jr, Dixon CM, Kusek JW, et al. The long-term effect of doxazosin, finasteride, and combination therapy on the clinical progression of benign prostatic hyperplasia. N Engl J Med 2003;349:2387-98.

4. Cho KJ, Kang SH, Kim HS, Koh JS, Kim JC. Effect of 5-alpha reductase inhibitor on storage symptoms in patients with benign prostatic hyperplasia. Int Neurourol J 2011;15:152-7.

5. Hamilton W, Sharp D. Symptomatic diagnosis of prostate cancer in primary care: a structured review. Br J Gen Pract 2004;54:617-21.

6. Guess HA. Benign prostatic hyperplasia and prostate cancer. Epi- demiol Rev 2001;23:152-8.

7. Kim TH, Han DH, Lee KS. The prevalence of lower urinary tract symptoms in korean men aged 40 years or older: a populationbased survey. Int Neurourol J 2014;18:126-32.

8. Choi H, Chang YS, Kim JB, Kang SH, Park HS, Lee JG. Analysis of initial baseline clinical parameters and treatment strategy associated with medication failure in the treatment of benign prostatic hyperplasia in Korea. Int Neurourol J 2010;14:261-6.

9. Tolis G, Ackman D, Stellos A, Mehta A, Labrie F, Fazekas AT, et al. Tumor growth inhibition in patients with prostatic carcinoma treated with luteinizing hormone-releasing hormone agonists. Proc Natl Acad Sci U S A 1982;79:1658-62.

10. Gioeli DG. The promise of novel androgen receptor antagonists. Cell Cycle 2010;9:440-1.

11. Lehrer S, Stone NN, Droller MJ, Stock RG. Association between American Urologic Association (AUA) urinary symptom score and disease stage in men with localized prostate cancer. Urol Oncol 2002;7:73-6.

12. Barry MJ, Williford WO, Chang Y, Machi M, Jones KM, WalkerCorkery E, et al. Benign prostatic hyperplasia specific health status measures in clinical research: how much change in the American Urological Association symptom index and the benign prostatic hyperplasia impact index is perceptible to patients? J Urol 1995;154: 1770-4.

13. Ebara S, Manabe D, Kobayashi Y, Tanimoto R, Saika T, Nasu Y, et al. The efficacy of neoadjuvant androgen deprivation therapy as a prostate volume reduction before brachytherapy for clinically localized prostate cancer. Acta Med Okayama 2007;61:335-40.

14. Frazier A, Kaufman N, Rosemberg S, Frazier R, Lutz M, Maitland C. et al. Prostate volume reduction induced by neoadjuvant androgen ablation in preparation for permanent radioactive seed implantation. Radiother Oncol 2000;55(Suppl 1):77-8.

15. Axcrona K, Aaltomaa S, da Silva CM, Ozen H, Damber JE, Tankó $\mathrm{LB}$, et al. Androgen deprivation therapy for volume reduction, lower urinary tract symptom relief and quality of life improvement in patients with prostate cancer: degarelix vs goserelin plus bicalutamide. BJU Int 2012;110:1721-8.

16. Gleave ME, Goldenberg SL, Chin JL, Warner J, Saad F, Klotz LH, et al. Randomized comparative study of 3 versus 8-month neoadjuvant hormonal therapy before radical prostatectomy: biochemical and pathological effects. J Urol 2001;166:500-6.

17. Langenhuijsen JF, van Lin EN, Hoffmann AL, Spitters-Post I, Alfred Witjes J, Kaanders JH, et al. Neoadjuvant androgen deprivation for prostate volume reduction: the optimal duration in prostate cancer radiotherapy. Urol Oncol 2011;29:52-7. 
18. Sanghani MV, Schultz D, Tempany CM, Titelbaum D, Renshaw $\mathrm{AA}$, Loffredo $\mathrm{M}$, et al. Quantifying the change in endorectal magnetic resonance imaging-defined tumor volume during neoadjuvant androgen suppression therapy in patients with prostate cancer. Urology 2003;62:487-91.

19. Kucway R, Vicini F, Huang R, Stromberg J, Gonzalez J, Martinez A. et al. Prostate volume reduction with androgen deprivation therapy before interstitial brachytherapy. J Urol 2002;167:2443-7.

20. Whittington R, Broderick GA, Arger P, Malkowicz SB, Epperson $\mathrm{RD}$, Arjomandy $\mathrm{B}$, et al. The effect of androgen deprivation on the early changes in prostate volume following transperineal ultrasound guided interstitial therapy for localized carcinoma of the prostate. Int J Radiat Oncol Biol Phys 1999;44:1107-10.

21. Wilson S. Downsizing and prostate cancer. Rev Urol 2004;6 Suppl 7:S19-24.

22. Klarskov LL, Klarskov P, Mommsen S, Svolgaard N. Effect of endocrine treatment on voiding and prostate size in men with prostate cancer: a long-term prospective study. Scand J Urol Nephrol 2012; 46:37-43.

23. Anderson J, Al-Ali G, Wirth M, Gual JB, Gomez Veiga F, Colli E, et al. Degarelix versus goserelin (+antiandrogen flare protection) in the relief of lower urinary tract symptoms secondary to prostate cancer: results from a phase IIIb study (NCT00831233). Urol Int 2013;90:321-8.

24. Russo A, Castiglione F, Salonia A, Benigni F, Rigatti P, Montorsi F, et al. Effects of the gonadotropin-releasing hormone antagonist ganirelix on normal micturition and prostaglandin E(2)-induced detrusor overactivity in conscious female rats. Eur Urol 2011;59: 868-74.

25. Bahk JY, Kim MO, Park MS, Lee HY, Lee JH, Chung BC, et al. Gonadotropin-releasing hormone $(\mathrm{GnRH})$ and $\mathrm{GnRH}$ receptor in bladder cancer epithelia and GnRH effect on bladder cancer cell proliferation. Urol Int 2008;80:431-8.

26. Rick FG, Schally AV, Block NL, Halmos G, Perez R, Fernandez JB, et al. LHRH antagonist Cetrorelix reduces prostate size and gene expression of proinflammatory cytokines and growth factors in a rat model of benign prostatic hyperplasia. Prostate 2011;71:736-47.

27. Siejka A, Schally AV, Block NL, Barabutis N. Mechanisms of inhibition of human benign prostatic hyperplasia in vitro by the luteinizing hormone-releasing hormone antagonist cetrorelix. BJU Int 2010;106:1382-8. 